\title{
ANALISIS PERKEMBANGAN PERBANKAN SYARIAH TERHADAP PERTUMBUHAN UMKM MELALUI KEBIJAKAN MONETER DI INDONESIA
}

\author{
Milla Naeruz \\ Fakultas Ekonomi, Universitas Islam Sumatera Utara \\ Email :milla.naeruz@fe.uisu.ac.id
}

\begin{abstract}
ABSTRAK
Industri perbankan terus mengalami peningkatan tetapi UMKM masih banyak yang tidak tersentuh oleh industri ini. Padahal pemerintah sudah menggalakkan UMKM dan banyak memberikan stimulus berupa bunga yang rendah, namun mengapa ini masih menjadi dilema oleh UMKM. Penelitian ini adalah penelitian yang membahas hubungan perkembangan perbankan syariah atau pembiayaan syariah terhadap UMKM melalui kebijakkan Bank Indonesia yaitu suku bunga BI. Dan dalam penelitian ini dapat diperoleh kesimpulan bahwasanya peningkatan secara langsung pembiayaan syariah berhubungan negatif terhadap kebijakkan Bank Indonesia dalam hal ini adalah kebijakkan menentukan bunga dan secara langsung pembiayaan syariah berhubungan positif terhadap perkembangan UMKM. Dan secara tidak langsung suku bunga BI tidak terlalu berhubungan terhadap UMKM. Secara keseluruhan bahwasanya perkembangan UMKM tidak berhubungan terhadap suku bunga BI karena UMKM hanya butuh pembiayaan untuk modal agar dapat meningkatkan usaha mereka. Penelitian ini menggunakan data sekunder dari tahun 2008 sampai dengan agustus 2019 yang diperoleh dari data BPS, OJK dan Bank Indonesia serta diolah menggunakan Aplikasi Path.
\end{abstract}

Kata kunci : Pendapatan, Pembiayaan Syariah, Suku Bunga BI, UMKM.

\begin{abstract}
The banking industry continues to experience improvement, but many UMKM are still untouched by this industry. Even though the government has promoted UMKM and provided many stimuli in the form of low interest, why is this still a dilemma for UMKM. No. This research is a study that discusses the relationship between the developments of Islamic banking/Islamic financing on UMKM through Bank Indonesia policies, namely the BI interest rate. And in this study it can be concluded that the direct increase in Islamic financing has a negative relationship with Bank Indonesia policy in this case, the policy of determining interest and directly Islamic financing has a positive relationship with the development of UMKM. And indirectly the BI rate is not very related to UMKM. Overall, the development of UMKM is not related to the BI rate because UMKM only need financing for capital in order to increase their business. The study used secondary data from 2008 to August 2019 which was obtained from data from BPS, OJK and Bank Indonesia and processed using the Path Application.
\end{abstract}

Keywords : Revenue, Syariah Finance, BI Interest Rate, UMKM. 


\section{PENDAHULUAN}

Industri perbankan syariah nasional terus tumbuh dengan laju pertumbuhan bervariasi sesuai dengan kondisi ekonomi dan berbagai faktor yang mempengaruhi perkembangannya sejak lebih dari dua dekade, tepatnya sejak 1992. Otoritas perbankan, baik ketika diemban Bank Indonesia maupun setelah menjadi tugas dan kewenangan Otoritas Jasa Keuangan (OJK), secara konsisten terus melakukan berbagai upaya untuk mendorong perkembangan industri perbankan syariah nasional agar dapat tumbuh sehat, berkelanjutan dan semakin memiliki kontribusi positif dalam mendukung pembangunan ekonomi yang berkualitas. Potensi manfaat dari perkembangan

Industri perbankan syariah bagi kemaslahatan ekonomi nasional sudah banyak dibuktikan dan dirasakan dari perjalanan sejarah perbankan syariah Indonesia dan negara lain. Perkembangan industri perbankan syariah yang lebih cepat dan besar setidaknya memberikan kontribusi positif dalam mendukung inklusi keuangan khususnya bagi masyarakat yang menginginkan layanan keuangan yang memenuhi prinsip syariah pada berbagai level usaha. Mulai dari usaha korporasi hingga masyarakat akar rumput yang belum terjangkau layanan keuangan formal. OJK menyusun rencana strategis baru untuk perkembangan industri perbankan syariah nasional. Rencana strategis tersebut dinamakan Roadmap Perbankan Syariah Indonesia 2015-2019. Penamaan dan rentang periode perencanaan disesuaikan dengan roadmap sektoral jasa keuangan lainnya di OJK. Roadmap ini diharapkan dapat memberikan panduan arah yang ingin dicapai, termasuk inisiatif terencana untuk mencapai sasaran pengembangan yang ditetapkan serta mewujudkan sasaran pengembangan industri perbankan syariah nasional.

Pada periode 2010-2015, laba perbankan syariah dan unit syariah dalam lima tahun terakhir juga tumbuh 73 persen menjadi Rp. 1,8 triliun. Namun, melambatnya perekonomian domestik serta melemahnya nilai tukar rupiah membuat laba perbankan syariah pada 2015 hanya tumbuh tipis tiga persen dari tahun sebelumnya. Islamic Finance Development Report 2018 dari Thomson Reuters menunjukkan Indonesia masuk dalam daftar sepuluh negara dengan pasar keuangan syariah yang tumbuh pesat di dunia. Indonesia berada di peringkat ke-10 dari 131 negara dalam Islamic Finance Development Index 2018 dengan skor 50. Di bawah ini grafik perbandingan jumlah UMKM dan pendapatan bank syariah:

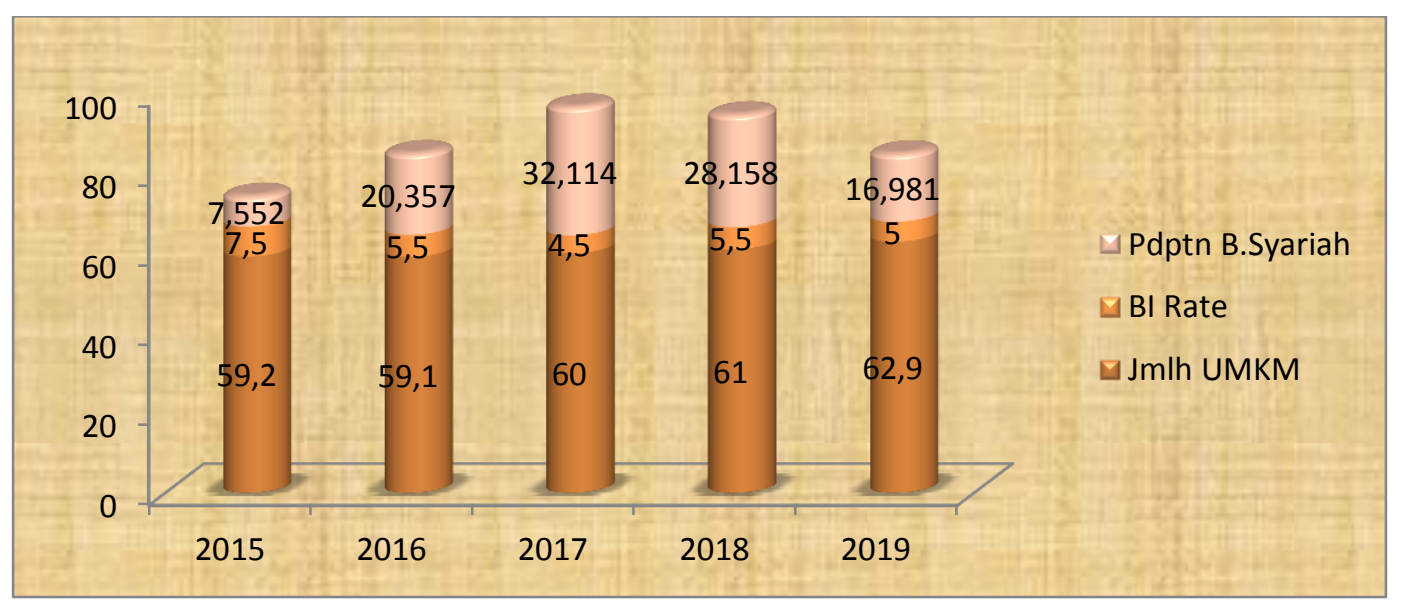




\section{Grafik 1. Perbandingan Jumlah UMKM dan Pendapatan Bank Syariah}

Kinerja anak usaha syariah dan unit usaha syariah (UUS) bank BUMN terus meningkat. Ambil contoh anak usaha PT. Bank Negara Indonesia Tbk (BNI) lewat BNI syariah yang per akhir 2018 lalu berhasil memperoleh laba sebesar Rp.
416 miliar, diperoleh dari transaksi digital, hasanah card (kartu pembiayaan), cash management dan bisnis remitansi. Di bawah ini grafik perbandingan jumlah penduduk Indonesia dan jumlah UMKM Indonesia :

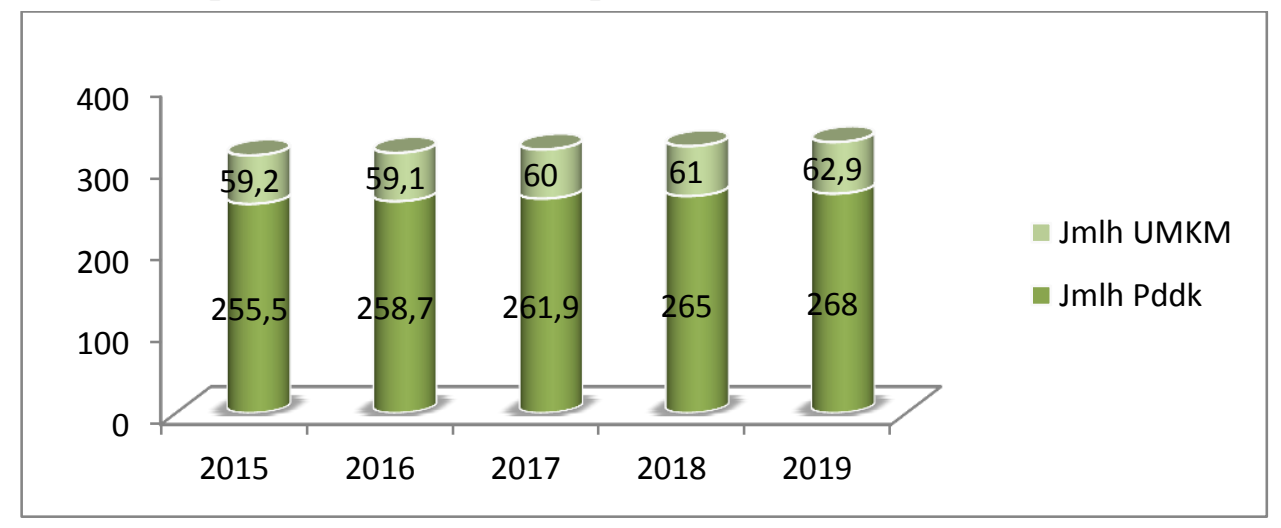

\section{Grafik 2. Perbandingan Jumlah Penduduk Indonesia dan Jumlah UMKM Indonesia}

Dari berbagai data yang diperoleh seperti data Badan Perencanaan Pembangunan Nasional, Badan Pusat Statistik, dan United Nation Population Fund, memprediksi jumlah pelaku usaha mikro, kecil, dan menengah (UMKM) di Indonesia pada 2018 sebanyak 58,97 juta orang. Sedangkan jumlah penduduk Indonesia pada tahun 2018 diprediksi mencapai 265 juta jiwa artinya hampir $25 \%$ dari penduduk Indonesia mengembangkan usaha UMKM.

Kementerian Koperasi dan Usaha Kecil Menengah (Kemenkop UKM) menyatakan bahwasannya sebanyak 3,79 juta usaha mikro, kecil, dan menengah (UMKM) sudah memanfaatkan platform online dalam memasarkan produknya. Jumlah ini berkisar 8 persen dari total pelaku UMKM yang ada di Indonesia, yakni 59,2 juta Untuk menumbuhkan jumlah pelaku UMKM yang berselancar di dunia maya, Kemenkop UKM dan Kementerian Komunikasi dan Informatika (Kemkominfo) bersama dengan para pelaku e-commerce berencana membuat program 8 Juta UMKM Go Online. Lewat kerja sama ini, pemerintah juga berharap dapat mempercepat transformasi UMKM di Indonesia menuju digital. Kemenkop menyebut, selain memberdayakan UMKM, gerakan ini akan membantu memberikan akses keuangan pada wirausaha. Kemenkop akan membantu dan memastikan produk yang dihasilkan UMKM layak bersaing dan kapasitasnya cukup sehingga mendapatkan kepercayaan dari sumber pendanaan. I Wayan Dipta menyatakan bahwa "Dalam rangka memasuki bisnis online ini, kami perlahan membenahi UMKM-UMKM kita dengan membenahi kualitas produk dan standarisasi produk mereka". Kementerian Koperasi juga akan membantu peningkatan Sumber Daya Manusia (SDM) dan akses terhadap sumber-sumber pembiayaan, karena salah satu alasan kenapa UMKM sampai saat ini belum juga maju adalah karena kekurangan modal.

Tak bisa dipungkiri bahwa modal usaha kerap menjadi hambatan bagi masyarakat untuk memulai dan mengembangkan usaha. Selain karena 
akses terhadap modal usaha terasa sulit bagi masyarakat, ketakutan untuk meminjam dan berutang menjadi alasan umum yang menghambat Perbankan pun mulai agresif menyalurkan kredit kepada UMKM. Bisnis UMKM tidak lagi dipandang sebagai bisnis kelas dua. Terbukti, penyaluran kredit ke sektor UMKM lambat laun mengalami pertumbuhan. Secara umum pertumbuhannya lebih tinggi dibandingkan total kredit perbankan.

\section{TINJAUAN PUSTAKA}

\section{UMKM}

Menurut Rudjito (2003), pengertian UMKM adalah usaha yang punya peranan penting dalam perekonomian negara Indonesia, baik dari sisi lapangan kerja yang tercipta maupun dari sisi jumlah usahanya.

\section{Menurut Primiana}

(2009) pengertian UMKM adalah pengembangan empat kegiatan ekonomi utama yang menjadi motor penggerak pembangunan Indonesia, yaitu; industri manufaktur, agribisnis, bisnis kelautan, sumber daya manusia. Selain itu, Primiana (2009) juga mengatakan bahwa UMKM dapat diartikan sebagai pengembangan kawasan andalan untuk mempercepat pemulihan perekonomian untuk mewadahi program prioritas dan pengembangan berbagai sektor dan potensi. Sedangkan usaha kecil merupakan peningkatan berbagai upaya pemberdayaan masyarakat.

\section{Pendapatan}

\section{Menurut Winardi (1997),} pendapatan adalah seluruh uang atau hasil material lainnya yang diterima seseorang atau rumah tangga selama jangka waktu tertentu dalam suatu kegiatan ekonomi. Menurut Niswonger (2006) pendapatan adalah jumlah yang diminta kepada pelanggan atas barang atau jasa yang diberikan kepadanya. Menurut Swanburg (2000) pendapatan adalah pemasukan dari penjualan produk dan pelayanan. Menurut Keynes (1936), pendapatan adalah determinan primer dari seberapa banyak orang yang memilih untuk mengonsumsi

\section{Bank Syariah}

Menurut Dahlan (2004) bank
syariah merupakan bank yang
menjalankan usaha perbankan dengan
berdasar ataupun memperhatikan prinsip-
prinsip syariah yang tertuang di dalam Al-
Qur'an dan Hadist.

Menurut Sudarsono (2003) bank syariah merupakan salah satu lembaga keuangan negara yang memberikan kredit dan jasa-jasa perbankan lainnya di dalam lalu lintas pembayaran dan peredaran uang yang beroperasi dengan berdasarkan prinsip-prinsip agama Islam atau pun prinsip syariah.

Menurut A. Perwataatmadja, dkk (1992) pengertian bank syariah adalah bank yang beroperasi dengan mengikuti prinsip-prinsip syariah ataupun islami yang tata cara pelaksanaannya didasarkan pada ketentuan Al-Qur'an dan Hadist.

Menurut UU No. 21 Tahun 2008, perbankan syariah yaitu segala sesuatu yang berkaitan bank syariah dan unit usaha syariah yang mencakup kelembagaan, kegiatan usaha, hingga proses pelaksanaan kegiatan usahanya. Bank syariah merupakan bank yang menjalankan aktivitas usahanya dengan menggunakan landasan prinsip-prinsip syariah yang terdiri dari BUS (Bank Umum Syariah), BPRS (Bank Perkreditan Rakyat Syariah), dan UUS (unit Usaha Syariah).

\section{Kebijakan Moneter}

Kebijakan moneter adalah kebijakan yang diambil oleh bank sentral atau Bank Indonesia dengan tujuan memelihara dan mencapai stabilitas nilai mata uang yang dapat dilakukan antara lain dengan pengendalian jumlah uang yang beredar di masyarakat dan penetapan 
suku bunga. Kebijakan moneter meliputi langkah-langkah kebijakan yang dilaksanakan oleh bank sentral atau Bank Indonesia untuk dapat mengubah penawaran uang atau mengubah suku bunga yang ada, dengan tujuan untuk memengaruhi pengeluaran dalam perekonomian. Tujuan kebijakan moneter tidak statis, namun bersifat dinamis karena selalu disesuaikan dengan kebutuhan perekonomian suatu negara. Akan tetapi, kebanyakan negara menetapkan empat hal yang menjadi tujuan dari kebijakan moneter, yaitu:

1. Pertumbuhan ekonomi dan pemerataan pendapatan.

2. Kesempatan kerja.

3. Kestabilan harga.

4. Keseimbangan neraca pembayaran

\section{Penelitian Terdahulu}

1. Menurut Arafah \& Nugroho (2016), Perbankan syariah memiliki hubungan yang erat dengan pelayanan keuangan kepada segmen bisnis mikro dan kecil. Implikasi hubungan tersebut adalah perbankan syariah harus memiliki produk yang sesuai dengan kebutuhan pengusaha mikro dan kecil yang notabene mereka adalah low income people. Lebih lanjut, beberapa pakar dalam keuangan Islam meyakini bahwa bank syariah adalah sebagai solusi bagi masyarakat berpenghasilan rendah (low income people) yang memang mereka tidak bisa mendapatkan fasilitas kredit atau pembiayaan dari bank-bank konvensional dikarenakan tidak dapat memenuhi persyaratan-persyaratan seperti tersedianya agunan (unbankable).

2. Berdasarkan hasil penelitian menggunakan tiga indikator keuangan inklusif Bank Indonesia yaitu access, usage, dan quality menunjukkan bahwa Bank Pembiayaan Rakyat Syariah sejauh ini telah berhasil menjaga dan meningkatkan kapasitasnya dalam memberikan akses, menyalurkan pembiayaan, dan rasio keuangan (Rifa'i, 2017),

3. Prosedur pelaksanaan pemberian kredit secara syariah serta cara mencegah terjadinya kredit macet. Berdasarkan penelitian ini penulis menyarankan agar pengawasan terhadap kinerja karyawan dalam melayani nasabah serta pengawasan kepada penerima kredit lebih aktif agar dapat mengetahui perkembangan usaha nasabah sehingga bisa mencegah terjadinya kredit macet. (Pato, 2013)

4. Perbankan syariah telah melakukan segala sistem yang telah ditetapkan sesuai dengan UU No. 21 Tahun 2008 tentang perbankan syariah yaitu memberikan pembiayaan berdasarkan akad yang tidak bertentangan dengan prinsip syariah yaitu bagi hasil yang tidak merugikan pihak nasabah sehingga dapat menjalankan usahanya. Bank Indonesia (BI) mencatat penyaluran pembiayaan syariah pada sektor usaha mikro, kecil, dan menengah (UMKM) mencapai 70\% dari total pembiayaan, atau sebesar Rp. 58 triliun hingga akhir September 2012. Hal ini membuktikan bahwa bank syariah memiliki peran penting dalam pemberdayaan UMKM. (Amah, 2013)

5. The Islamic banking allocation for UMKM in Makassar has flucktuative improvement (2010-2011). Although its contribution for Micro Finance is not yet optimum, it has great prospects with respect to the quality of UMKM that never receives budgets. (Kara, 2013)

\section{METODE PENELITIAN}

Penelitian didefinisikan oleh banyak penulis sebagai suatu proses yang sistematik. Mendefinisikan penelitian 
ilmiah sebagai penyelidikkan sistematik, terkontrol, empiris dan kritis tentang fenomena sosial yang dibimbing oleh teori dan hipotesis tentang dugaan yang berhubungan dengan fenomena sosial yang dibimbing oleh teori dan hipotesis tentang dugaan yang berhubungan dengan fenomena tersebut. Tujuan penelitian ini adalah untuk memperoleh bukti mengenai pengaruh peningkatan UMKM melalui pembiayaan syariah.

Penelitian ini menggunakan pendekatan kuantitatif, dimana pendekatan telah ditentukan sebelumnya menggunakan data sekunder dan data ber bentuk numeric. Menghubungkan variabel dalam masalah dan hipotesis.data kuantitatif, yaitu data dalam bentuk angka-angka atau data kualitatif yang diangkakan (Sugiyono, 2014). Data sekunder dengan jenis runtun waktu (time series) pada kurun waktu 2003 - 2018. Metode pengumpulan data dalam penelitian ini adalah pengumpulan data sekunder yang diperoleh dari Bank Indonesia, BPS (Badan Pusat Statistik) serta teknik kepustakaan yaitu dengan mengumpulkan data dari buku, jurnal, dan hasil penelitian serta sumber bacaan atau bahan tulisan yang relevannya dengan tesis ini

\section{Teknik Analisis Data (Analisis Jalur Path)}

Path analisis merupakan analisis yang digunakan untuk kajian hubungan yang berbentuk sistem. Kata hubungan merujuk kepada nilai korelasi. Path analysis menjelaskan hubungan langsung dan tidak langsung antar variabel baik itu independen maupun dependen variabel. Dengan begitu, persyaratan multikolinear tidak berlaku di path analysis, karena justru multikolinear itulah yang akan dibahas dalam Path untuk menunjukkan hubungan tidak langsung. Hubungan langsung dan hubungan tidak langsung ini nantinya akan dijumlahkan untuk mengetahui total hubungan variabel independen ke variabel dependennya. Path analysis bersifat confirmatory, bukan explanatory. Jadi, variabel-variabel yang digunakan dalam path harus didasari oleh teori atau setidaknya penelitian terdahulu. Berbeda halnya dengan regresi yang mengasumsikan cateris paribus, bisa digunakan untuk explanatory yang hasilnya dikonfirmasi dengan path analysis ini. Jika anda hanya ingin mengkonfirmasi teori bahwa ada hubungan $\mathrm{X}$ dan $\mathrm{Y}$ dan tidak menggunakan rumus persamaan untuk memprediksi nilai $\mathrm{Y}$, maka path bisa menjadi pertimbangan. Asumsi dasar yang digunakan dalam path adalah model linear dan semua perubah diukur dalam skala minimal interval. Jadi antara $\mathrm{X}$ dan $\mathrm{Z}$ ada dua hubungan, yakni hubungan langsung yang mengarah ke $\mathrm{Z}$, dan hubungan tidak langsung melalui $\mathrm{V}$ maupun melalui $\mathrm{Y}$. Variabel $\mathrm{V}$ dan $\mathrm{Y}$ inilah yang dinamakan dengan variabel mediator. Variabel ini yang bisa memperkuat hubungan $\mathrm{X}$ dan $\mathrm{Y}$ bisa juga sebaliknya, justru melemahkan. Nanti bisa dilihat dari tanda negatif atau positif nilai korelasinya. Untuk menguji hipotesis-hipotesis dalam penelitian ini, maka akan digunakan persamaan jalur sebagai berikut

$$
\begin{array}{ll}
Y_{1} & =\alpha+\beta_{11} X_{1+} \beta_{12} X_{2}+\varepsilon 1 \\
Y_{2} & =\alpha+\eta_{21} X_{1}+\eta_{22} X_{2}+\eta_{23} Y_{1}+\varepsilon 2
\end{array}
$$

Keterangan :

$$
\begin{array}{ll}
\mathrm{Y}_{1} & =\text { Kebijakan Moneter } \\
\mathrm{Y}_{2} & =\text { Jumlah UMKM } \\
\mathrm{X}_{1} & =\text { Pendapatan Perbankan Syariah } \\
\mathrm{X}_{2} & =\text { Jumlah Pembiayaan Syariah } \\
\alpha & =\text { Konstan } \\
\beta_{1}, \beta_{2}, & =\text { Koefisien } \\
\eta_{1}, \eta_{2} & =\text { Koefisien } \\
\varepsilon_{1}, \varepsilon_{2}, & =\text { Error }
\end{array}
$$


Nilai koefisien regresi sangat menentukan sebagai dasar analisis. Hal ini berarti jika koefisien $\beta$ bernilai negatif ( + ) maka dapat dikatakan terjadi pengaruh searah antara variabel independen dengan variabel dependen. Sedangkan bila koefisien nilai $\beta$ bernilai negatif (-) hal ini menunjukkan adanya pengaruh negatif dimana kenaikan nilai variabel independen akan mengakibatkan penurunan nilai variabel dependen.
Menurut Ghozali (2014) ketepatan dari fungsi regresi sampel dalam menaksir nilai aktual dapat diukur dari goodness of fit-nya. Secara statistik diukur dari nilai koefisien determinasi $\left(\mathrm{R}^{2}\right)$, nilai statistik $\mathrm{F}$ (uji kelayakan model) dan nilai stati stik $\mathrm{t}$ (uji signifikan parameter individual).

\section{HASIL DAN PEMBAHASAN}

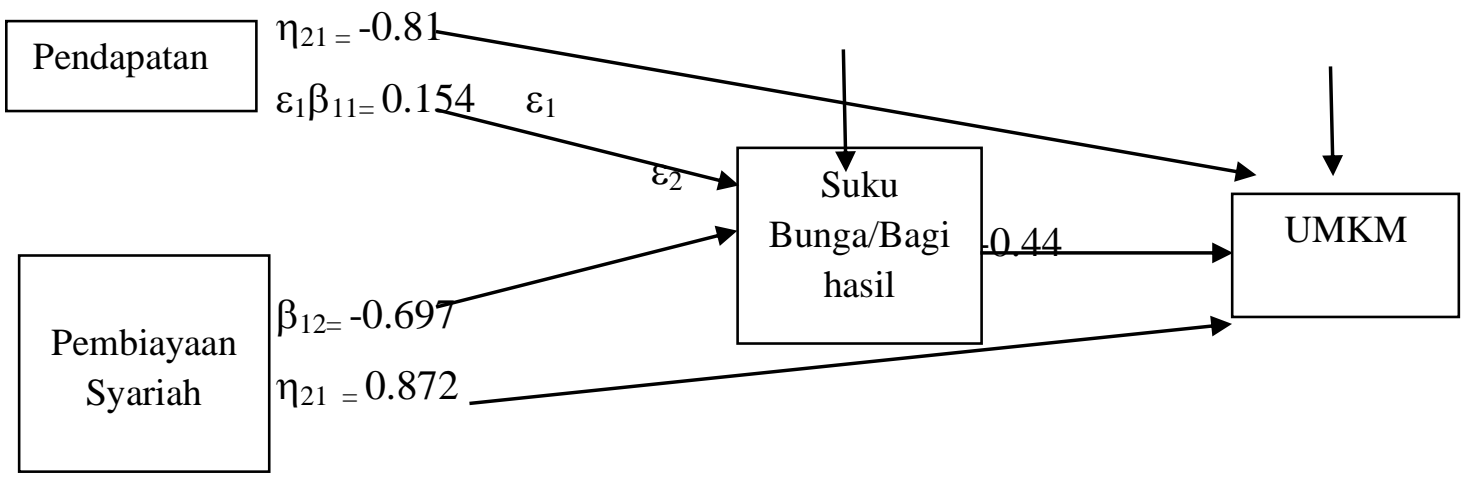

Gambar 1. Hasil Output Penelitian

\section{Efek Langsung}

$$
\begin{array}{ll}
\mathrm{Y}_{1} & =\alpha+\beta_{11} \mathrm{X}_{1+} \beta_{12} \mathrm{X}_{2}+\varepsilon_{1} \\
\mathrm{Y}_{1} & =\alpha+0.154 \mathrm{X}_{1}-0.697 \mathrm{X}_{2}+\mathrm{e}_{1} \\
\mathrm{Y}_{2} & =\alpha+\eta_{21} \mathrm{X}_{1}+\eta_{22} \mathrm{X}_{2}+\eta_{23} \mathrm{Y}_{1}+\varepsilon_{2} \\
\mathrm{Y}_{2} & =\alpha-0.81 \mathrm{X}_{1}+0.872 \mathrm{X}_{2}-0.44 \mathrm{Y}_{1}+\varepsilon_{2}
\end{array}
$$

a. $X_{1}$ Berhubungan dengan $Y_{1}$ (Pendapatan Berhubungan Positif terhadap Kebijakan Moneter (Suku Bunga Acuan BI) dan Tidak Signifikkan

Artinya Apabila suku bunga acuan BI naik $1 \%$ maka pendapatan pembiayaan syariah bertambah sebesar 1.54 milyar rupiah tetapi tidak signifikan atau tidak terlalu ada dampaknya. Dikarenakan kenaikkan suku bunga dalam hal ini bagi hasil akan menyebabkan pendapatan bunga/bagi hasil akan bertambah.

b. $X_{2}$ Berhubungan Negatif terhadap $Y_{1}$ (Jumlah Pembiayaan Syariah Berhubungan Negatif terhadap
Kebijakan BI (Suku Bunga Acuan BI) dan Signifikan

Artinya apabila suku bunga acuan BI naik $0.697 \%$ maka jumlah pembiayaan syariah akan turun 1 unit. Kenaikan suku bunga mengakibatkan terjadinya kenaikan harga atau inflasi, inflasi menyebabkan naiknya harga bahan mentah dan biaya biaya operasional lainnya hal ini akan berdampak terhadap laba atau keuntungan UMKM yang beroperasi masih dalam tipe kecil. Jika UMKM memperoleh laba yang sedikit bagaimana mungkin dia akan mengembangkan usahanya sementara untuk mengembangkan usahanya dia membutuhkan modal yang tidak sedikit dan pembiayaan yang diharapkan oleh UMKM tersebut. Dan UMKM akan mengurungkan niatnya untuk meminjam, karena tidak ada yang minjam akhirnya perbankan/pembiayaan akan mengurangi assetnya salah satunya adalah kantornya. 
c. $\mathrm{X}_{1}$ Berhubungan Negatif terhadap $\mathrm{Y}_{2}$ (Pendapatan Berhubungan Negatif terhadap UMKM) tetapi Tidak Signifikan

Artinya Apabila UMKM bertambah, maka pendapatan bank syariah akan berkurang. Berarti bank syariah telah melakukan kewajibannya dalam membantu kemajuan UMKM dengan menyalurkan pinjaman ke UMKM

d. $\mathrm{X}_{2}$ Berhubungan Positif terhadap $\mathrm{Y}_{2}$ (Jumlah Pembiayaan Syariah Berhubungan Positif terhadap UMKM) dan Signifikan

Artinya apabila jumlah pembiayaan bertambah 1 maka UMKM akan tumbuh sebesar 872. Artinya pembiayaan sangat berperan dalam kemajuan UMKM sebagai pemberi modal kepada para UMKM yang ingin memperbesar usahanya sampai dengan menambah cabang usahanya.

e. Y1 Berhubungan Negatif terhadap Y2 (Suku Bunga Berpengaruh Negatif terhadap UMKM) dan Tidak Signifikan

Artinya apabila BI sebagai pengambil kebijakan moneter menaikan suku bunga acuannya $1 \%$ maka jumlah UMKM akan berkurang sebesar 44 ribu.

\section{Efek Tidak Langsung}

$\mathrm{X} 1 \longrightarrow \mathrm{Y} 1 \longrightarrow \mathrm{Y} 2=\beta_{11} \mathrm{X}_{1} \mathrm{x} \eta 23 \mathrm{Y} 1$

$=0.158 \times-0.44$

$=-0.069$ (karena lebih besar dari sig 0,05)

yang berarti tidak berpengaruh Secara tidak langsung hubungan antara jumlah pendapatan pembiayaan syariah terhadap UMKM tidak berpengaruh melalui bunga acuan BI.

$\mathrm{X}_{2} \longrightarrow \mathrm{Y} 1 \longrightarrow \mathrm{Y} 2=\beta_{12} \mathrm{X}_{1} \mathrm{x} \eta_{23} \mathrm{Y} 1$

$=-0.697 \times-0.44$
$=0.306$ (lebih besar dari sig 0,05) berarti itu tidak berpengaruh. Secara tidak langsung hubungan jumlah pembiayaan syariah terhadap UMKM melalui kebijakan BI yaitu suku bunga acuan tidak berpengaruh.

\section{Total Efek}

$=-0.069+0.306$

$=0.237$ (lebih besar dari sig 0.05) Artinya secara keseluruhan jumlah pendapatan pembiayaan syariah, jumlah pembiayaan syariah tidak berpengaruh melalui suku bunga acuan BI.

Dapat kita simpulkan bahwasanya UMKM tidak terlalu mempermasalahkan kebijakan BI dalam nenaikkan ataupun menurunkan suku bunga BI itu dikarenakan UMKM sangat membutuhkan peranan bank syariah sebagai penopang modal dalam meningkatkan usaha mereka. Oleh sebab itu sebaiknya pemerintah dalam hal ini Bank Indonesia (BI) sebagai otoritas moneter harus sangat berhati-hati terhadap menentukan kebijakannya dikarenakan ada UMKM yang perlu perhatian khusus dari pemerintah. Sedangkan UMKM saat ini berkontribusi besar di tengah pertumbuhan ekonomi kita yang lemah saat ini.

\section{KESIMPULAN}

Berdasarkan hasil penelitian di atas dapat dibuat kesimpulan bahwa jumlah pendapatan syariah secara langsung berdamapak negatif terhadap UMKM tetapi tidak signifikan. Karena usaha UMKM umumnya adalah pengusaha kecil yang sangat tidak memahami tentang keuangan. Jumlah pembiayaan syariah secara langsung berdampak positif terhadap UMKM dan signifikan dikarenakan UMKM adalah usaha kecil yang sangat membutuhkan bantuan ataupun perhatiah khusus dari pemerintah. Sedangkan kebijakan suku bunga BI tidak berpengaruh terhadap 
UMKM. Artinya UMKM tidak terlalu mempermasalahkan suku bunga, karena mereka beranggapan kalau usahanya besar maka mereka pasti bisa membayar kewajiban mereka. Disarankan kepada pemerintah agar dapat membuat pelatihan untuk UMKM yaitu latihan membuat pembukuan, latihan dalam meningkatkan kualitas produk dan latihan memasarkan produk mereka agar dapat bersaing go Internasional.

\section{DAFTAR PUSTAKA}

A. Perwataatmadja, Karnaen dan Syafi'i Antonio. 1992. Apa dan Bagaimana Bank Syariah. Dana Bhakti Wakaf. Yogyakarta.

Amah, N. 2013. Bank Syariah dan UMKM dalam Menggerakkan Roda Perekonomian Indonesia : Suatu Kajian Literatur. Assets : Jurnal Akuntansi dan Pendidikan, 2(1).

Arafah, W., \& Nugroho, L., 2016. Maqhashid sharia in Clean Water Financing Business Model at Islamic Bank. International Journal of Business and Management Invention, 5(2), 2232.

Dahlan, Siamat. 2004. Manajemen Lembaga Keuangan, Edisi Keempat. Lembaga Penerbit Fakultas Universitas Indonesia. Jakarta.

Ghozali, 2014. Aplikasi Analisis Multivariate dengan Program SPSS. Penerbit UNDIP. Semarang.

Kara, M. 2013. Konstribusi Pembiayaan Perbankan Syariah Terhadap Pengembangan Usaha Mikro Kecil Dan Menengah (UMKM) Di Kota Makassar. Ahkam Jurnal Ilmu Syariah, 13(2).

Keynes, John M. 1936. The General Theory of Employment, Interest and Money. Harcourt Brace. New York.
Niswonger. 2006. Prinsip Prinsip Akuntansi. Airlangga. Jakarta.

Pato, S. 2013. Analisis Pemberian Kredit Mikro Pada Bank Syariah Mandiri Cabang Manado. Jurnal Riset Ekonomi, Manajemen, Bisnis Dan Akuntansi, 1(4).

Primiana, Ina. 2009. Menggerakkan Sektor Riil UKM \& Industri. Alfabeta. Bandung.

Rifa'i, A. 2017. Peran Bank Pembiayaan Rakyat Syariah dalam Mengimplementasikan Keuangan Inklusif Melalui Pembiayaan UMKM. IKONOMIKA, 2(2).

Rudjito. 2003. Strategi Pengembangan UMKM Berbasis Strategi Bisnis. Makalah yang di sampaikan pada Seminar Peran Perbankan dalam Memperkokoh Ketahanan Nasional Kerjasama Lemhanas RI Dengan BRI.

Sudarsono, Heri. 2003. Bank dan Lembaga Keuangan Syari'ah Deskripsi dan Ilustrasi. Ekonisia. Yogyakarta.

Sugiyono. 2014. Metode Penelitian Pendidikan Pendekatan Kuantitatif, Kualitatif, dan $R \& D$. Alfabeta. Bandung.

Swanburg, R.C. 2000. Pengantar Kepemimpinan dan Manajemen Keperawatan. Alih Bahasa: Suharyati Samba. EGC. Jakarta.

Winardi. 1997. Azas-azas Marketing. Penerbit Alumni. Bandung. 